University of Nebraska - Lincoln

DigitalCommons@University of Nebraska - Lincoln

Educational Psychology Papers and

Publications

Educational Psychology, Department of

January 1998

Conjoint Behavioral Consultation and Social Skills Training:

Enhancing the Play Behaviors of Boys With Attention Deficit

Hyperactivity Disorder

\author{
Denise L. Colton \\ University of Utah \\ Susan M. Sheridan \\ University of Nebraska-Lincoln, ssheridan2@unl.edu
}

Follow this and additional works at: https://digitalcommons.unl.edu/edpsychpapers

Part of the Educational Psychology Commons

Colton, Denise L. and Sheridan, Susan M., "Conjoint Behavioral Consultation and Social Skills Training: Enhancing the Play Behaviors of Boys With Attention Deficit Hyperactivity Disorder" (1998). Educational Psychology Papers and Publications. 10.

https://digitalcommons.unl.edu/edpsychpapers/10

This Article is brought to you for free and open access by the Educational Psychology, Department of at DigitalCommons@University of Nebraska - Lincoln. It has been accepted for inclusion in Educational Psychology Papers and Publications by an authorized administrator of DigitalCommons@University of Nebraska - Lincoln. 


\title{
Conjoint Behavioral Consultation and Social Skills Training: Enhancing the Play Behaviors of Boys With Attention Deficit Hyperactivity Disorder
}

\author{
Denise L. Colton and Susan M. Sheridan \\ University of Utah
}

In this study, we demonstrate the use of conjoint behavioral consultation (CBC) as a model to join parents and educators in the shared development and implementation of interventions for students. A behavioral social skills intervention was delivered in the context of $C B C$ to enhance the cooperative peer interactions of young boys diagnosed with attention deficit hyperactivity disorder (ADHD). A multiple probe design across participants was used. The mothers and teachers of 3 boys between the ages of 8 and 9 years who were diagnosed with ADHD and who were exhibiting performance deficits in their cooperative play behaviors served as consultation participants. Direct observation data suggest that the behavioral social skills intervention implemented within the context of CBC was related to increases in positive, cooperative interactions with peers. In general, positive changes were noted from pretreatment to posttreatment administrations of the Social Skills Rating System (Gresham \& Elliott, 1990). Measures of treatment acceptability, treatment integrity, and social validity also yielded positive results. This study lends support to the use of $C B C$ as a means of joining parents and teachers in the delivery of effective behavioral interventions.

The benefits of partnerships between parents and educators are clear (see Christenson, 1995). Numerous studies have found that when parents work

Correspondence should be addressed to Susan M. Sheridan, Department of Educational Psychology, 327 Milton Bennion Hall, University of Utah, Salt Lake City, UT 84112. E-mail: Sheridan@gse.utah.edu 
collaboratively with teachers and are involved with their children's learning at school, children have greater chances for success. The importance of a strong home-school partnership has been repeatedly identified as a critical factor in the success of students. When parents are involved in their children's education and school activities, students report more positive attitudes toward school (Christenson, 1990). Moreover, the relation between parental involvement and student achievement appears to be independent of family background effects, suggesting that parents of diverse backgrounds can positively influence school success by becoming active participants in their children's education (Robinson \& Fine, 1994).

The most common forms of parental involvement follow a "school to home transmission model" (Swap, 1992, p. 58). In this model, school personnel identify goals for students without two-way communication with families. Teachers are generally responsible for the task of educating students, and problems identified by school personnel are reported to parents. An alternative conceptualization of home-school collaboration emphasizes a partnership philosophy. This philosophy emphasizes mutual respect and an explicit, shared commitment to supporting the educational experiences of all students. In such a model, parents are viewed as assets who share in educational goal setting, collaborative problem solving, and mutual decision making (Welch \& Sheridan, 1995). Exemplary home-school partnership models that demonstrate effective, cooperative relationships between parents and school personnel are described by Comer and Haynes (1991), Levin (1987), and Christenson (1995), to name a few. However, few models are available that provide an operational framework for educators and parents to address specific concerns of individual children. Conjoint behavioral consultation (CBC; Sheridan, Kratochwill, \& Bergan, 1996) is one such model.

\section{CBC}

$C B C$ is defined as a structured model of service delivery that joins parents and teachers in collaborative problem solving with the assistance of a consultant-psychologist. It is carried out in four stages: problem identification, problem analysis, treatment implementation, and treatment evaluation (Sheridan et al., 1996). In this model, the relation between home and school is viewed as a cooperative and interactive partnership with shared ownership of a problem. Among the assumptions of $C B C$ are that parents and teachers will share information, learn from each other, value each other's input, and incorporate each other's insights into intervention plans. As such, collaborative problem solving between the home and school 
systems is believed to afford the greatest benefits (Sheridan \& Kratochwill, 1992; Sheridan et al., 1996).

The utility of $\mathrm{CBC}$ as a process by which to structure and support behavioral interventions has been evaluated in previous research. The first study investigated the treatment of socially withdrawn elementary school children, and CBC resulted in a substantial increase in social initiations for clients in both home and school settings (Sheridan, Kratochwill, \& Elliott, 1990). Another investigation was conducted with children experiencing academic underachievement. Participants were elementary school children who frequently failed to complete math assignments or completed the math assignments with low levels of accuracy. For 3 participants, a home note and self-instruction manual was used to address the performance deficit. For 3 additional participants, $\mathrm{CBC}$ was added to the procedures. Results indicated that although all children demonstrated improvements in math completion and accuracy, achievement gains were greater and more stable in the $\mathrm{CBC}$ condition than in the home-note/instruction-manual condition. Further, treatment integrity and acceptability as well as maintenance of treatment gains were greater when $\mathrm{CBC}$ was an active intervention component (Galloway \& Sheridan, 1994; additional case studies are reported in Sheridan et al., 1996). This study extends previous research by investigating its efficacy with 3 boys diagnosed with attention deficit hyperactivity disorder (ADHD) who were experiencing deficits in specific social behaviors.

\section{ADHD AND SOCIAL SKILLS}

ADHD is defined as "a developmental disorder characterized by developmentally inappropriate degrees of inattention, overactivity, and impulsivity" (Barkley, 1990, p. 47). Although these three behavioral features are the hallmark of ADHD, a serious associated problem for children with this disorder concerns their social skills and peer relationships (Landau \& Moore, 1991; Pelham \& Bender, 1982). Children with ADHD are often described as bossy, intrusive, impulsive, aggressive, and disruptive. These behaviors serve to elicit extreme ratings of dislike from their peers, often leading to social rejection (Pelham \& Bender, 1982; Whalen \& Henker, 1985).

As many as $50 \%$ to $60 \%$ of children with ADHD experience social problems (Barkley, 1990). Further, social problems and peer rejection problems tend to be maintained over time and are quickly reestablished even when moving into a new peer group. Children with ADHD seem unable to modulate their behavior in response to situational demands (Abikoff, 1985), and may not benefit from past experiences because they have diffi- 
culty taking the time to consider consequences before speaking or acting (Silver, 1992).

Weiss and Hechtman (1993) discussed several long-term follow-up studies of children with ADHD. In their extensive review, they reported that children who experience ADHD with antisocial behavior patterns are at risk for developing problems later in life. These problems include occupational difficulties, relationship and marital difficulties, alcoholism, antisocial and criminal behavior, and psychiatric disorders.

Children with ADHD experience a wide variety of problems related to their disorder. However, most intervention research has focused on behavioral and academic concerns. The social problems of children with ADHD are less frequently prioritized in research.

\section{PURPOSE}

The purpose of this study was to evaluate the efficacy of an intervention package comprised of CBC and social skills training (SST) in improving the cooperative play behaviors of 3 boys with ADHD. Although one goal of consultation services is to individualize services for children based on unique case needs, the experimental design required continuity of programs across participants. Therefore, a behavioral social skills intervention with four general strategies (coaching, self-monitoring, home-school communication, positive reinforcement) was employed across participants. Individualization occurred as parents and teachers jointly identified primary social problems and coconstructed specific intervention tactics. Direct measures of social behaviors in analogue settings and behavioral checklists served as the dependent variable. Measures of treatment acceptability, treatment integrity, and social validity were also included.

Specific research questions posed in this study included (a) Will the child participants demonstrate increased rates of positive, cooperative interactions with peers in relation to the implementation of the treatment package (CBC and SST)?; (b) Will the treatment package produce changes in parent, teacher, and student ratings on the Social Skills Rating System (SSRS; Gresham \& Elliott, 1990)?; (c) Will consumers (children, teachers, and parents) find the consultation and SST procedures acceptable?; (d) Will the CBC and SST procedures be delivered in a manner consistent with their design?; and (e) Will the treatment package increase students' rates of cooperative interactions with peers to a level comparable to either a nonreferred comparison peer or to a level that parents and teachers find meaningful, or both? 


\section{METHOD}

\section{Participants}

Three White elementary school boys were participants in the study. Their mothers $(n=3)$ and classroom teachers $(n=3)$ served as consultees. Although not a central or planned aspect of the study, all parents were from low socioeconomic conditions. All child participants were between the ages of 8 and 9 years with cognitive abilities in at least the average range as measured by a standardized test of intelligence. Prior to the beginning of the study, all participants were diagnosed with ADHD by independent physicians. One was classified as having learning disabilities and received part-time instruction in a resource program; the others had no educational classification and received no special educational services.

All boys, prior to participation in this study, were receiving a medication treatment that helped to manage some of their ADHD symptoms. They maintained their medicated status throughout all phases of the study, with a brief (1-day) exception for Child 2. Child 1 was taking a prescribed daily dose of Clonidine (patch form). Child 2 was taking a prescribed dose of Ritalin twice daily. Child 3 was taking a prescribed daily dosage of Dexedrine. Participants were on their prescribed medication at the time of all intervention procedures and direct observation sessions.

Each child's mother and teacher completed two behavioral checklists: the Child Behavior Checklist (CBCL; Achenbach \& Edelbrock, 1991a)/Teacher Report Form (TRF; Achenbach \& Edelbrock, 1991b), and the Attention Deficit Disorders Evaluation Scale-Home and School Versions (ADDES-H; ADDES-S; McCarney, 1991). $T$ scores $(M=50, S D=10)$ on relevant CBCL factors ranged from 68 to 80 for Social Problems and from 65 to 67 for Attention Problems. Similar factor scores on the TRF ranged from 69 to 87 and from 57 to 80 for Social Problems and Attention Problems, respectively. On the ADDES-H, participants received ratings between the 1st and 15th percentiles (standard scores are not available for this instrument). On the ADDES-S, percentile scores ranged from 5 to 16 . Thus, results supported the diagnosis of ADHD, even though participants were on medication when parents and teachers completed the checklists.

Prebaseline screening was conducted to elicit general concerns of parents and teachers. In semistructured screening interviews, all parents and teachers reported that the boys evidenced problems with peer social interactions. Specifically, all children were reported to demonstrate problems maintaining positive and cooperative interactions with peers. Informal direct observations were conducted by Denise L. Colton to validate parent and teacher reports. These included observations of approximate time engaged in 
cooperative play behaviors and frequency counts of negative interactions. During screening, participants demonstrated between approximately $10 \%$ and $30 \%$ cooperative interactions with peers.

\section{CONSULTATION STAGES AND TREATMENT COMPONENTS}

Based on the information obtained during screening, the focus of consultation across all cases was identified as increasing positive cooperative play behaviors (i.e., positive interactive social behaviors such as praising, conversing, smiling, and sharing; and positive noninteractive behaviors or game-related behaviors if the child was clearly engaged in play with another child, such as waiting for a turn). CBC was carried out in four stages (problem identification, problem analysis, treatment implementation, and treatment evaluation) and involved three structured interviews (problem identification, problem analysis, and treatment evaluation). Standardized CBC interview forms were used in this study (see Sheridan et al., 1996). Denise L. Colton (a doctoral student in school psychology with extensive training in behavioral consultation, assessment, and interventions) served as the consultant in each case.

\section{Problem Identification}

A problem identification interview (PII) was conducted by the consultant with each of the mother-teacher consultee dyads. PIIs were conducted in teachers' classrooms after school. Total time commitment for completing PIIs averaged approximately $60 \mathrm{~min}$. The purposes of this interview were to discuss behaviors relevant to social skills that were problematic for each client and to develop procedures by which parents and teachers could collect anecdotal data across all experimental phases. Specifically, consultees used narrative recording procedures to record observational information regarding the types of difficulties the child encountered with peers (e.g., teasing) as well as outcomes of these encounters (e.g., hitting, crying, running away).

\section{Problem Analysis}

The problem analysis stage of $\mathrm{CBC}$ was initiated via the problem analysis interview (PAI). PAIs were conducted between 5 and 14 days after PIIs for 
each participant (lengthier periods were required for 2 participants due to scheduled school breaks). PAIs averaged approximately $40 \mathrm{~min}$ and were conducted in teachers' classrooms.

Problem analysis and PAIs involved two phases. In the analysis phase, the consultant and consultees discussed the narrative information collected by consultees and conditions surrounding clients' problem behavior(s). For example, it was noted that Child 3's social difficulties were often related to isolative behaviors. Antecedents included not being asked to play and failing to initiate interactions on his own. When he did ask others to play, it was reported that he was often teased and rejected, thereby reinforcing his isolative play.

The narrative information collected by parents and teachers was used to select target subskills that would be the focus of training. This was accomplished in two phases. First, a list of cooperative behaviors based on McGinnis and Goldstein (1984) was presented to parent-teacher pairs. Then the parent, teacher, and consultant together identified seven cooperative behaviors that were believed to be priority subskills. These seven priority subskills became the content of SST. Table 1 lists the priority subskills taught to each participant.

In the plan phase of the PAI, a 15-day behavioral SST program was discussed among the consultant and consultees. This program served as an overarching structure within which individualization occurred per child. In other words, similar behavioral strategies were used across children (i.e., social skills coaching and role play, self-monitoring of recess behaviors, a home-school communication system, and positive reinforcement). However, details of individual programs (i.e., program tactics) were coconstructed by parents and teachers with the assistance of the consultant. For example, each parent-teacher pair determined (a) the specific subskills to be included on "friendship recipe cards," (b) when and where coaching would occur, (c) the person responsible for coaching, (d) reinforcement

TABLE 1

Cooperative Play Behaviors Targeted per Participant

Participant 1

Participant 2

Participant 3

\begin{tabular}{lll}
\hline Using self-control & Using self-control & Expressing feelings \\
Responding to teasing & Responding to teasing & Responding to teasing \\
Problem solving & Problem solving & Problem solving \\
Playing a game & Playing a game & Playing a game \\
Praising a peer & Avoiding trouble & Praising a peer \\
Dealing with anger & Dealing with anger & Accepting no (peers) \\
Accepting consequences & Showing sportsmanship & Dealing with losing \\
\hline
\end{tabular}


schedules, and (e) the specific reinforcers to be earned by individual children and their mode of delivery (e.g., reinforcement menu). We discuss general strategies in the following section.

Coaching and role play. Coaching and role-play procedures were implemented as primary skill-training mechanisms. Specifically, steps for each cooperative play subskill were written on note cards termed "friendship recipe cards," which served as a medium for coaching. Steps were adapted from the skillstreaming curriculum (McGinnis \& Goldstein, 1984). The back side of each card contained general recess rules, including "what to do" (e.g., play nicely with others; practice your recipe goal during at least one recess today) and "what not to do" (e.g., no hitting or fighting, no teasing or name calling). Coaching instruction cards were included with each friendship recipe card, instructing the coach (the teacher or parent) to (a) review recess rules, (b) explain the steps in the chosen skill, (c) discuss examples and nonexamples of the skill, and (d) role play a scenario with the child. On alternate days, each child drew a recipe card to practice for 2 school days. On Day 15 of the intervention, each child was allowed to choose a favorite card from those already practiced and repeat that skill.

For Child 1 and Child 3, teachers provided coaching of each target skill in their classrooms before the first recess each day. During the PAI, the teacher of Child 2 indicated that she did not have adequate time to provide the coaching, so it was agreed that the procedure would be carried out by this child's mother at home before school each day. The daily coaching sessions lasted approximately 5 to $7 \mathrm{~min}$ each.

Self-monitoring. As part of the behavioral intervention, participants self-monitored their behaviors during three recess periods per day. After the child was coached in the skill identified on the friendship recipe card, he was responsible for practicing the skill on the playground and monitoring his performance. A home-school note provided a place for the child to rate performance of his target skill (whether he used the skill, when and with whom he used the skill, and how it went). Each child also rated how well he followed the recess rules during each recess period on a scale of 1 (poor) to 4 (excellent). The teacher completed this section with the child by discussing his play behaviors each day. Unknown to the child, teachers made random casual observations during recess to confirm that the child's self-ratings were reasonably honest. Due to logistical and practical constraints, these observations were informal and thus did not generate objective behavioral data. 
Home-school communication system. An important component of the treatment package involved systematic home-school communication. This was accomplished through a daily two-page home-school note that included (a) recess rules, (b) the skill being practiced, (c) the self-monitoring component as described previously, and (d) questions for the child's parent to review his daily behaviors (e.g., "Did I discuss my friendship recipe card with mom or dad and tell them about when I practiced it today?"; "How many points did I earn?"; "Was the home note signed and returned to school yesterday?"). Points were awarded for successful completion of each part of the home note. Teachers and parents were responsible for filling out the information on the home-school note and had five and eight questions to complete, respectively. Information included on the note was obtained via direct questions to the child, whose input was necessary for completing the note. An outline of all components of the home note/self-monitoring form appears in Table 2.

Positive reinforcement. In addition to teacher and parent praise for engaging in cooperative interactions with peers, the participants also re-

TABLE 2

Home Note Communication System and Self-Monitoring Form

I. Recess rules

A. What to do

1. Play nicely with others.

2. Try to spend most of your recess time playing cooperatively with others.

3. Practice your recipe goal during at least one recess today.

B. What not to do

1. No hitting or fighting.

2. No teasing or name calling.

3. No playing alone for all of recess; try to play with others.

II. Self-ratings of friendship recipe skill use

A. Skill to practice (fill in the blank with daily skill from recipe card).

B. Indicate whether skill was used (Yes $=15$ points, $N o=0$ points).

C. Indicate when skill was used.

D. Indicate with whom skill was used.

E. Rate self on quality of skill use (great, okay, not so good).

F. Rate self on recess rule adherence (excellent, good, okay, poor).

III. Parent-child discussion

A. Discuss friendship recipe with parent and discuss performance (Yes $=5$ points, No $=0$ points).

B. Total points earned.

C. Complete point chart at home.

D. Determine if home reward was earned based on points accumulated.

E. Rate overall day (great, okay, not so good).

F. Sign and return home note to school (Yes $=5$ points, $N o=0$ points). 
ceived points for practicing their skill recipes (worth 15 points), following the recess rules (assessed by self-report and worth up to 15 points), discussing their performance with their parents (5 points), and returning the home note to school each day (5 points). Thus, up to 40 points were possible daily. A daily reward was provided by parents if 35 points were attained each day. Reinforcers varied across children and included money, visits with friends, kite flying, ice-cream cones, etc.

\section{Treatment Implementation and Evaluation}

During the treatment implementation stage, intervention plans were implemented and behavioral data were collected. All programs were begun on the most immediate school day following PAIs. Interventions lasted for 15 consecutive school days.

Treatment evaluation interviews (TEIs) were conducted at the end of the 15-day period to aid in determining the success of the treatment plan. Children were present at these interviews to elicit their perceptions of the treatment program. Because parents, teachers, and students were generally pleased with the children's progress, fading procedures were instituted. Specifically, all participants agreed to continue to review and practice their friendship recipe cards informally for the remainder of the school year (ranging between 2 and 5 weeks). Formal self-monitoring was discontinued on the playground. The parents of Child 1 and Child 3 decided to continue to communicate with a simplified home note; however, these notes did not carry any point values. These parents agreed to provide weekly rewards based on satisfactory performance. With one exception, TEIs were conducted after school. They required an average of $20 \mathrm{~min}$ to complete.

\section{OUTCOME MEASURES}

Outcome measures used in this study included direct observations and behavioral checklists. Measures of treatment acceptability, treatment integrity, and social validity were also obtained.

\section{Direct Observations}

Direct observations were conducted by independent observers to measure positive social, negative aggressive, and isolative behaviors in small-group play settings. Cooperative interactions with peers was the target behavior of greatest interest, defined as all verbal and nonverbal positive social behaviors that are either interactive (e.g., praising, conversing, smiling, and 
sharing) or noninteractive game-related behaviors (if the child was clearly engaged in play with another child; e.g., waiting for a turn in a game). Observers also conducted observations of negative aggressive behaviors (i.e., all verbal and nonverbal behaviors directed toward another peer that are considered abusive, highly critical, derogatory, or potentially injurious; e.g., name calling, teasing, bossing) and isolative behaviors (i.e., all nonsocial behavior such as engaging in a game alone, not conversing with others in the group, or watching others play without participating).

Direct observational data were collected prior to, during, and following the consultation/social skills interventions. Specifically, 20-min observations were conducted in play situations one or two times weekly, using 10 -sec partial-interval procedures. A room was provided with various play materials such as games, puzzles, Legos, and Viewmasters. The target child and 4 to 5 other classmates were told that they could play with any of the toys in the room, alone or together, and that hurting others was prohibited. Denise L. Colton videotaped the sessions but generally had no interaction with the children. The classmates were chosen by teachers who were asked to identify "average" children with no social skills problems; those same children participated in all phases of the study. Sessions were conducted in an empty classroom in the afternoons. Each session was videotaped and then coded by one of two independent, trained, blind observers in random order. Thirty-three percent of the tapes were coded by both observers for purposes of establishing interrater reliability. Kappa was computed to determine the reliability among raters controlling for chance agreement, with a resulting coefficient of $k=.83$. Interrater agreement was also computed by summing the number of intervals on which observers agreed, divided by the total number of intervals, and multiplied by 100 . Overall, 92\% agreement between observers was achieved.

\section{Behavioral Rating Scales}

The SSRS-Parent, Teacher, and Student Forms (SSRS-P, SSRS-T, SSRS-S; Gresham \& Elliott, 1990) were administered to all participants and consultees prior to and following the consultation/social skills intervention (prior to the PII and following the TEI). The SSRS-P is a 70-item questionnaire designed to measure behavior of children and adolescents in two broad areas: social skills and problem behaviors. Factor analysis of the SSRS-P revealed four factors: Cooperation, Assertion, Responsibility, and Self-Control. The SSRS-T is a 57-item questionnaire designed to measure behavior of children in three broad areas: social skills, problem behaviors, and academic competence. Factor analysis of the SSRS-T revealed three factors: Cooperation, Assertion, and Self-Control. The SSRS-S is a 34-item 
questionnaire designed to measure the students' own perceptions regarding their social skills. The SSRS-S contains four factors: Cooperation, Assertion, Empathy, and Self-Control. Overall SSRS results are reported as standard scores in which $M=100$ and $S D=15$. The Total score and Cooperation factor score on the SSRS were of particular interest in this study.

\section{Treatment Acceptability}

Consultee acceptability. Parents' and teachers' acceptability of CBC was assessed on a revised version the Behavior Intervention Rating System (BIRS; Von Brock \& Elliott, 1987). The BIRS consists of 24 items rated on a 6-point Likert scale. Parents and teachers assessed acceptability of CBC across three factors: Acceptability, Effectiveness, and Time to Effect. Minor revisions of the original wording of the BIRS made the instrument applicable to consultation procedures. Parents and teachers completed the revised BIRS following their treatment evaluation interview.

Client acceptability. Children's acceptability of the social skills intervention was assessed by the Children's Intervention Rating Profile (CIRP; Witt \& Elliott, 1985). The CIRP is a 6-item questionnaire rated on a 5-point Likert scale. Questions pertain to fairness and acceptability of the intervention from the child's perspective.

\section{Treatment Integrity}

CBC integrity. Treatment integrity for $\mathrm{CBC}$ procedures was assessed via audiotaped analysis of all interviews. The consultant's performance of specific objectives of each consultation interview (Kratochwill \& Bergan, 1990) was coded by one of two independent, trained observers. Thirty-three percent of the tapes (selected randomly and representing each CBC stage) were coded by both observers as a check for interrater agreement. Agreement was computed as the number of objectives on which observers agreed divided by the number of agreements plus disagreements, multiplied by 100. ${ }^{1}$ Agreement between the observers averaged $96 \%$.

\footnotetext{
${ }^{1}$ Kappa was computed to determine reliability between raters controlling for chance agreement. However, the coefficient is negatively affected when there is little variability across raters (e.g., all agree) and few items. The resulting kappa coefficient $(k=.28)$ is therefore not considered an accurate estimate of interrater agreement.
} 
Social skills intervention integrity. Treatment integrity of parents' and teachers' implementation of intervention procedures was assessed via completion of items on the home-school note. Parents' adherence to procedures was assessed by their response to eight items on the note, and teachers' adherence was assessed via five items, using similar self-report methods.

\section{Social Validity}

Social comparison. Social comparison procedures involved matching each student with one same-sex classmate, identified by classroom teachers as having adequate social skills (i.e., few or no problems interacting with peers). These comparison peers were involved in the analogue observation sessions. Specifically, an independent observer conducted six 10-min partial-interval observations of the positive, cooperative interactions of the comparison peer, who was selected randomly across students' baseline and treatment videotapes.

Subjective evaluation. Subjective evaluations involved the assessment of children's behaviors by parent and teacher ratings on the SSRS. Ratings were compared pretreatment and posttreatment to determine if parents' and teachers' perceptions of overall social skills fell within the average range after treatment.

\section{EXPERIMENTAL DESIGN AND DATA ANALYSIS}

A multiple probe design across participants was used to evaluate behavioral changes across baseline, treatment, and follow-up conditions. Five observations were conducted prior to intervention to establish baseline data for the 1st participant. Nine and six baseline observations were conducted for Participants 2 and 3, respectively (the baseline observations for participants in the extended baselines were staggered to reduce assessment reactivity). Follow-up probes were conducted at 1 and 3 weeks postintervention for Participants 1 and 2 and at 1 week postintervention for Participant 3.

Intervention conditions were initiated with the PAIs, conducted immediately prior to the onset of the social skills program. Intervention conditions lasted 15 school days for each participant. The intervention was 
applied to participants in a successive fashion after at least 3 intervention data points had been collected for the prior participant.

\section{RESULTS}

\section{Direct Observations}

Each child's averages in cooperative, isolative, and negative behaviors across baseline, treatment, and follow-up conditions are presented in Table 3. Likewise, Figure 1 presents direct observational data for all participants during all experimental phases: baseline, treatment, 1-week follow-up, and 3-week follow-up.

Overall, participants averaged $27 \%$ positive interactions with peers during the baseline phase; during treatment, they averaged $61 \%$ positive interactions. Baseline averages ranged from $24 \%$ to $31 \%$ positive interactions with peers; treatment averages ranged from $50 \%$ to $69 \%$. Each child made positive behavioral gains immediately upon treatment implementation, and they all increased their mean positive play behaviors with peers during treatment. Likewise, behaviors under extended baseline conditions (i.e., Child 2 at observation sessions $7-10$ and Child 3 at observation sessions 7-13) remained low and stable, unaffected by the administration of treat-

TABLE 3

Average Percentage of Positive, Isolative, and Negative Behaviors Across Experimental Phases

\begin{tabular}{lcccc}
\hline Child and Behavior & Baseline & Treatment & Follow-up & ODP $^{\mathrm{a}}$ \\
\hline Positive interactions & & & & \\
1 & 31 & 69 & 68 & 0 \\
2 & 26 & 50 & 55 & 50 \\
3 & 24 & 63 & 22 & 17 \\
Isolative play & & & & \\
1 & 64 & 29 & 28 & 0 \\
2 & 65 & 48 & 38 & 83 \\
3 & 75 & 37 & 78 & 17 \\
Negative behaviors & & & & \\
1 & 4 & 2 & 5 & - \\
2 & 9 & 2 & 8 & - \\
3 & 2 & 0 & 0 & - \\
\hline
\end{tabular}

Note. $\mathrm{ODP}=$ overlapping data points. Dashes indicate that percentages of overlapping data points were not computed for negative behaviors due to the low frequency of occurrence across all experimental phases (Scruggs, Mastropieri, \& Casto, 1987).

${ }^{\mathrm{a}}$ Percentage of overlapping data points between baseline and treatment conditions. 


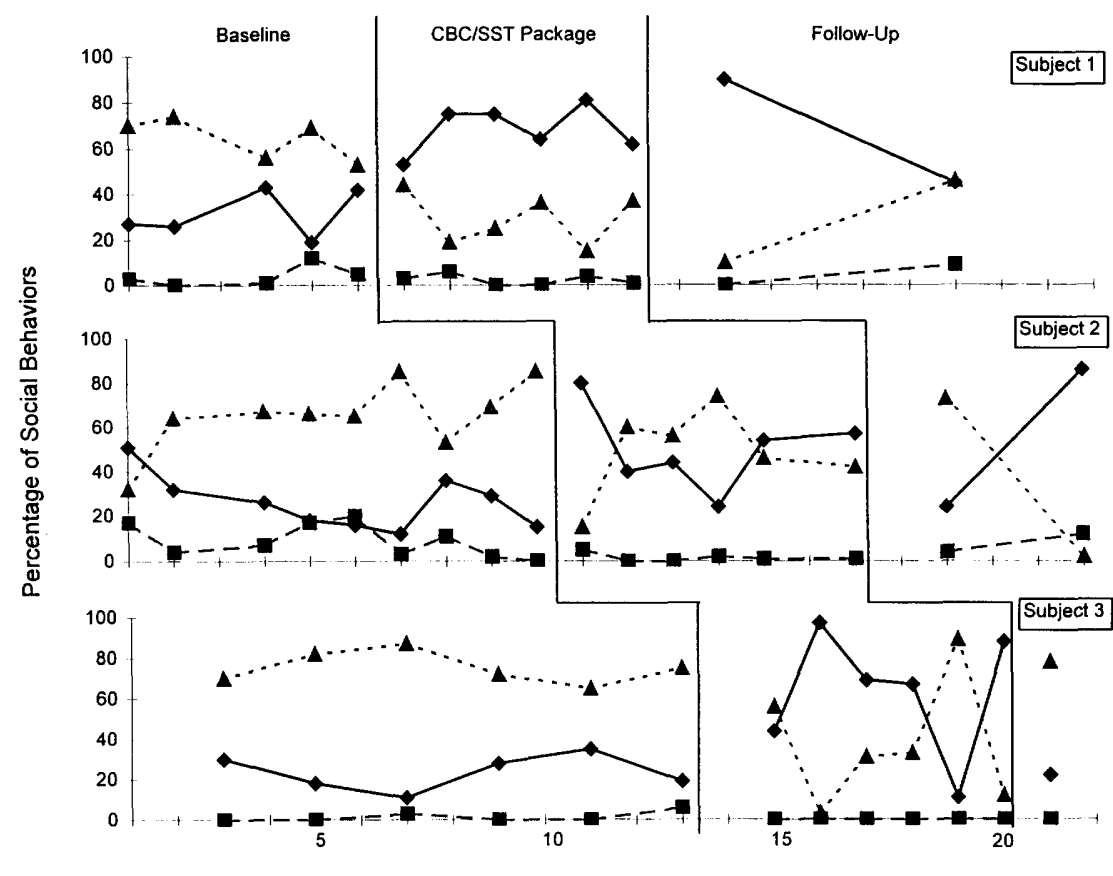

Observation Session

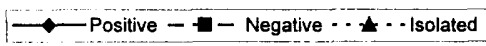

FIGURE 1 Percentage of positive, isolative, and negative behaviors across baseline, treatment, and follow-up conditions.

ments to other children (further ruling out a threat to the internal validity of the intervention).

Data trends for Participants 1 and 3 were generally stable and in the positive direction. ${ }^{2}$ There was no overlap between baseline and treatment data for Child 1, and the amount of overlap between baseline and treatment data for Child 3 was minimal $(17 \%)$. ${ }^{3}$ Taken together, behavioral data suggest that the treatment package exerted functional control for Participants 1 and 3 . On the other hand, data for Child 2 were variable with a high

\footnotetext{
${ }^{2}$ Within-phase stability was defined as $80 \%$ to $90 \%$ of the data points falling within $15 \%$ of the mean (Tawney \& Gast, 1984).

${ }^{3}$ Percentage of overlapping data points was calculated by counting the number of data points in the treatment phase that exceeded the highest data point in the baseline phase, divided by the total number of data points in the treatment phase, multiplied by 100 (Scruggs, Mastropieri, \& Casto, 1987).
} 
degree of overlap between baseline and treatment (50\%), suggesting little experimental control. (Recall that a variation in the coaching procedure occurred with this participant; his mother rather than the teacher provided the coaching instruction for each target skill.)

Follow-up data revealed mean improvements in the frequency of cooperative play behaviors for Participants 1 and 2 . However, a great deal of variability is present in these data. For Child 3, only one data point was available, and it was similar to this participant's baseline level of performance. Thus, there was little evidence for the maintenance of behavior changes over time for these students.

Although increases in cooperative play behaviors were the primary target of this study, direct observations of negative and isolative behaviors were also conducted to monitor their occurrence and determine potential side effects of the treatment package. Across participants, very few negative behaviors were observed during any experimental phase. Baseline levels of negative social behaviors showed little change from baseline to treatment, largely due to their limited occurrence overall. At baseline, negative social behaviors averaged $5 \%$ (range $=0-17 \%$ ) across participants. During treatment, averages decreased to $1.33 \%$ (range $=0-5 \%$ ). At follow-up, the average returned to the baseline level of $4.2 \%$. The child exhibiting the greatest amount of negative social behavior during baseline (Child 2; baseline mean $=9 \%)$ demonstrated a decrease during treatment $(M=2 \%)$. However, this child's negative behaviors returned to baseline levels at follow-up.

Some changes were noted in participants' isolative behaviors from baseline to treatment conditions. Across all participants, baseline levels of playing in isolation averaged $68 \%$. At treatment, levels of isolative play averaged $38 \%$. Although follow-up data are difficult to interpret due to the limited number of data points, the follow-up data average increased slightly from treatment levels to $48 \%$. Experimental control may have been exerted for at least 2 participants (Participants 1 and 3), considering the change in level from baseline to treatment (decreasing by $35 \%$ and $38 \%$, respectively) and the relatively low percentages of overlapping data points across baseline and treatment conditions ( 0 and $17 \%$, respectively). Child 2 also demonstrated a decrease of $17 \%$ in isolative behaviors; however, his data pattern resulted in $83 \%$ overlapping data points and his treatment levels remained generally high (treatment mean $=48 \%$ ). These findings parallel those from the cooperative play behavioral observations, which suggested functional control and changes in the positive direction for Participants 1 and 3 and little meaningful effect for Participant 2. 


\section{Self-Monitoring}

As part of the behavioral intervention, participants self-monitored their behaviors during three recess periods per day on a scale of 1 (poor) to 4 (excellent) and were asked to indicate the playground period during which they practiced their skill (morning, lunch, afternoon). Across all participants, average ratings of good were reported when skills were not being practiced. Mean ratings of excellent were reported when they actively practiced their skills.

Across all playground sessions, Child 1 provided self-ratings that averaged 3.46 (good; range $=1-4$ ). During those playground sessions when the skill was being practiced, this child received a mean of 3.9 (excellent). During those playground sessions when the skill was not being practiced, an average of 3.23 (good) was obtained. According to self-report, this child practiced his target skill on 11 of $15(73 \%)$ treatment days.

The self-monitoring data of Participant 2 revealed an average of 3.27 (good) across all playground sessions (range $=1-4$ ). For those playground sessions when this child was practicing his target skills, he obtained a mean of 3.63 (excellent). When not practicing the skills, he achieved an average of 3.16 (good). Participant 2 practiced his target skills on 8 of $15(53 \%)$ treatment days.

Self-monitoring data for Participant 3 revealed an average of 3.71 (excellent; range $=2-4$ ) across all playground sessions. During those sessions when the target skill was being practiced, a mean rating of 3.8 (excellent) was obtained. For those playground sessions when the skills were not being practiced, a mean of 3.59 (good-excellent) was achieved. This child practiced his skills on all $15(100 \%)$ of the treatment days.

\section{Behavioral Rating Scales}

Pretreatment and posttreatment total scores on the SSRS are presented in Table 4. All parent and teacher ratings (with the exception of the parent rating for Participant 1) indicated positive increases in overall social skills scores from pretreatment to posttreatment. Along with total social skills scores, changes in Cooperation factor scores were of secondary interest. When computed as $z$ scores, all parent and teacher Cooperation ratings (with the exception of the parent rating for Participant 1 ) reflected increases ranging from less than $1 S D$ to 1 and $2 S D$ s. 
TABLE 4

Pretreatment (Pre) and Posttreatment (Post) Scores on the Social Skills Rating System ${ }^{\mathrm{a}}$

\begin{tabular}{|c|c|c|c|c|c|c|}
\hline \multirow[b]{2}{*}{ Child } & \multicolumn{2}{|c|}{ Teacher } & \multicolumn{2}{|c|}{ Parent } & \multicolumn{2}{|c|}{ Student } \\
\hline & Pre & Post & Pre & Post & Pre & Post \\
\hline 1 & 79 & $94^{\mathrm{b}}$ & 79 & 79 & 116 & 109 \\
\hline 2 & 86 & 91 & 74 & $96^{\mathrm{b}}$ & 109 & 90 \\
\hline 3 & 85 & $102^{\mathrm{b}}$ & 93 & 96 & 121 & 124 \\
\hline
\end{tabular}

${ }^{a}$ Gresham and Elliott (1990). ${ }^{b}$ One $S D$ increase from pretreatment to posttreatment assessment.

\section{Treatment Acceptability}

Consultee acceptability. Parent and teacher acceptability of CBC was assessed with the BIRS. In general, parents and teachers reported that the procedures were acceptable (total mean item scores of 4.93 and 4.94 on a 6-point Likert scale, respectively). Mean item scores across the three factors suggested that consultees perceived the procedures to be generally acceptable and efficient (Acceptability factor mean $=5.4$; Time to Effect factor mean $=4.67$ ) but only moderately effective (Effectiveness factor mean $=4.0$ ). Items that parents endorsed as most favorable included "This model of consultation was a fair way to handle the child's problem behavior" and "I like the procedures used in this model of consultation." Among the items endorsed most favorably by teachers were "I would suggest the use of this consultation model to other teachers" and "I would be willing to use this model of consultation in the classroom setting again" (mean response $=6.0$ for each item; strongly agree).

Client acceptability. Children's acceptability of the intervention procedures was assessed by the CIRP. Children's responses suggested that they found the social skills intervention highly acceptable (4.67 on a 5-point Likert scale). Among the items endorsed most favorably by children were "I liked the plan" and "The plan would be good for other children" (mean response $=5.0$ for each item; strongly agree).

\section{Treatment Integrity}

CBC integrity. All CBC interviews were audiotaped, and the consultant's demonstration of specific objectives per interview (Kratochwill \& 
Bergan, 1990) was coded by independent, trained observers. Across all interviews, $98 \%$ of the objectives were achieved.

Social skills intervention integrity. Treatment integrity of the social skills intervention was assessed by specific questions on the home note and by computing the total percentage of home notes returned by the student. Specifically, parents' adherence to the general intervention procedures was assessed by their response to eight items on the home-school note (e.g., discuss the child's behavior at school, assess attainment of reward, provide reward); teachers' adherence was assessed by their response to five similar items. In all instances, all relevant home note items were completed by parents and teachers, suggesting $100 \%$ adherence to the social skills program. All participants returned home-school notes $100 \%$ of the time.

\section{Social Validity}

Social comparison. Social comparison observations were conducted for each participant. The comparison peer for Child 1 averaged $77 \%$ positive interactions over six 10-min observations (compared to $69 \%$ demonstrated by Child 1 during treatment). The comparison peer for Child 2 demonstrated an average of $67 \%$ positive interactions, compared to a treatment average of $50 \%$ for that participant. The comparison peer for Child 3 averaged $83 \%$ positive interactions, compared to $63 \%$ during treatment for the participant. Recall that the baseline averages for Participants 1, 2, and 3 were $31 \%, 26 \%$, and $24 \%$, respectively. These data suggest that all children increased their positive interactions to a point that approached the level of classroom comparison peers.

Subjective evaluation. The SSRS data were used as a means of evaluating parents' and teachers' ratings of posttreatment performance by comparing them to a national normative sample of same-age, same-sex peers. As indicated previously, teachers' ratings increased from standard scores in the below-average range to ratings in the average range posttreatment for Participants 1 and 3; parents' ratings increased in the same manner for Participant 2. Teachers' ratings on the Cooperation factor increased by at least $1 S D$ for all participants. Parents' ratings on the same factor increased in the same vein for Participants 2 and 3. 


\section{DISCUSSION}

One strength of this exploratory study is that it contributes to the small but growing body of research in a relatively new area of investigation. The treatment package composed of CBC and SST outlined in this study seems promising for use by professionals working with parents and teachers of young boys with ADHD who are experiencing problems related to their cooperative interactions with peers. Further, it demonstrates the role of parents and teachers as partners and coconstructors in the development of intervention tactics for children. For example, after closely observing the students' interactions with peers for 1 week, teachers and parents jointly chose the social subskills (e.g., using self-control) they considered most important. Similarly, when the teacher of Child 2 expressed concern about being able to spend time coaching the student, the student's mother readily volunteered to assume this role.

Anecdotal information collected during the study revealed that parents viewed their participation in $\mathrm{CBC}$ very favorably. Parents commented that they had never worked with teachers to jointly solve problems and that they liked the CBC format. Rather, their past experiences had consisted of teachers simply reporting problems to them. One parent commented that prior to $\mathrm{CBC}$, she had begun dreading calls from the school. She stated that she appreciated working on ideas for problem solutions with the teacher and consultant and having her opinions valued.

This study is also the first to include CBC with children with ADHD, aimed at increasing their positive interactions with peers. This research adds support to the handful of other studies that have demonstrated the effectiveness of $\mathrm{CBC}$ as a means of behavioral treatment delivery for schoolchildren (Galloway \& Sheridan, 1994; Sheridan \& Colton, 1994; Sheridan et al., 1990). The inclusion of behavioral rating scales and ancillary outcome measures investigating treatment acceptability, treatment integrity, and social validity are desirable features of the study. These measures are critical for practitioners to use in determining the acceptability and importance of their intervention procedures and in promoting socially valid and relevant changes in client behavior.

\section{Research Limitations}

Although the results of this study are encouraging, some research limitations are apparent. Due to the nature of these limitations, care must be exercised when interpreting the results, which should be considered exploratory at this time. 
Lack of a components analysis. A primary limitation of this study is its inability to determine the singular and collective effects of the two intervention components: CBC and SST. It must be emphasized that the independent variable in this study is conceptualized as a package intervention consisting of multiple elements. A components analysis was not conducted, making it impossible to identify the operative elements of the intervention package. In other words, the design used in this study does not allow for the measurement of the effects of CBC independent of SST. Therefore, the results of this study, although promising, are not conclusive at this time. Further research should investigate experimentally the effects of separate intervention components.

Lack of measurement in criterion settings. A second limitation of this study is the lack of a measure of cooperative play behavior in the criterion, treatment (i.e., playground) environment. The objective assessment of positive, negative, and isolative behaviors occurred in videotaped play situations that allowed the researchers to capture ongoing interactive behaviors (including verbal and nonverbal exchanges and subtle nuances of participants' behaviors). The only data available from playground settings are those reported in children's self-monitoring records, with no concomitant baseline data. It was originally planned to have the recess monitor also help rate the child as an added measure of reliability. However, teachers felt this was too great a burden due to varying schedules of recess monitors and also the large number of children being monitored (sometimes as many as one monitor for 75-100 children). It is interesting to note that there is some variability in participants' self-monitoring data (i.e., behavioral ratings were higher for playground situations when children reported practicing their skills vs. situations when they were not). This suggests that their playground behaviors may have been related to skill use (at least from the participants' potentially biased perceptions). It is also possible that their responses were biased based on their knowledge of conditions under which they were practicing target skills. Although it is difficult to draw unequivocal conclusions regarding the internal validity of the treatment package, it is promising that (a) behavioral changes occurred in the videotaped play situations in conjunction with the skill training; (b) self-monitoring on the playground suggested that positive behaviors were exhibited, particularly when skills were being practiced; and (c) improvements were seen in responses on behavioral rating scales. Future research should assess directly the effects of the $\mathrm{CBC} /$ social skills intervention in the treatment setting, with generalization probes to other play situations similar to those used in this study. 
Difficulties with baseline data. A third limitation of this study was difficulty interpreting the baseline data. First, Child 1 demonstrated a descending baseline trend for isolative behaviors, which continued into treatment. It should be noted that positive social behaviors were the specific intervention target and the primary dependent variable in this study. Although a slight ascending trend is apparent for this participant's positive social behaviors, changes in level and lack of overlapping data between baseline and treatment are encouraging.

Second, participants' baseline data were variable. Unfortunately, the need to deliver treatment in a timely fashion superseded the preferred research protocol of continuing baseline collection until stability was achieved. Given the nature of the behavior studied, it might be speculated that what is considered by statisticians a stable data series might not be achievable. Children's social interactions quite likely vary as a function of many factors (e.g., mood, health, antecedent and contextual conditions, presence or absence of others). It is interesting to note that the data obtained from observations of classroom comparison peers demonstrated similar variations that could not, by traditional definition, be considered stable.

Limited follow-up. A fourth study limitation is that very few followup data observations are available, and a great deal of variability is apparent at this experimental phase. Convincing follow-up data are apparent for Child 1 only; treatment effects did not generalize over time for Participants 2 and 3 at the 1-week follow-up or for Child 3 at the 3-week follow-up. Given the critical nature of social skills for boys with ADHD and the general intractability of negative social behaviors, procedures to strengthen generalization of treatment effects over time is necessary. This study was completed at the end of the school year, and data collection was terminated at an unfortunate point in time. It is likely that longer exposure to treatment conditions is necessary for participants to ADHD (Barkley, 1990), with continuous long-term follow-up incorporated into the experimental design.

Inconsistent treatment effects. A fifth limitation was the lack of consistent treatment conditions across all participants (i.e., Child 2's mother, rather than the teacher, delivered the social skills coaching procedure). This is acceptable from a process perspective due to the shared responsibility it invokes; however, the variation served to weaken the experimental design. Related to this is the lack of direct measurement of consultee behaviors in the implementation of treatment components. It is unknown whether this or other factors accounted for the large number of overlapping data points 
between the baseline and intervention data series for Child 2. The initial baseline data point for Child 2 was $51 \%$ positive interactions with peers, which was much higher than the other 8 baseline data points (range = $12-36 \%$ ). This outlier accounted for the high degree of overlap between the baseline and treatment series. Without this outlier, there would have been only $17 \%$ ( 1 data point) overlap with treatment data. Further, the one low point in Child 2's treatment data occurred on a day that the student had been experiencing various behavior difficulties, according to the teacher report (Observation Session 14). A discussion with the mother revealed that his stimulant medication had been left at a relative's house over the weekend and that he had not received his prescribed dose for 2 days. Nonetheless, these overlapping data points in Participant 2's data resulted in lack of demonstrable experimental control.

\section{Research Directions}

$\mathrm{CBC}$ is a relatively new approach to providing indirect services to parents and teachers of students with academic, social, or behavioral difficulties. It is necessary to systematically investigate the utility of the model, with consultees presenting diverse personal characteristics (e.g., ethnicity, educational level, socioeconomic status) and relationship factors (e.g., lack of motivation to work together, resistance to the collaborative process, history of interpersonal problems). Likewise, its efficacy with children with educational classifications (e.g., learning disabled, behaviorally disordered) is in need of investigation. Of particular interest may be its role as an aid in the integration of students with disabilities into regular classroom environments.

Several additional research directions are apparent. For example, one goal of $\mathrm{CBC}$ is to enhance the parent-teacher relationship and improve subsequent conjoint problem solving. Some anecdotal information is available from participants in this study; for example, the parents and teachers of Participants 1 and 3 continued a simplified home-school communication system for the remainder of the school year, and the parent of Child 3 reported that she planned to continue role-play practices of social skills with both of her children during the summer. However, systematic investigation of generalization effects over time and behaviors is necessary.

An important element of any behavioral intervention study is assessing the degree to which treatment agents implement specific plan components as designed (i.e., with integrity). Whereas many researchers have addressed this through self-monitoring procedures (e.g., Sheridan et al., 1990), direct assessment may be warranted in some cases. Likewise, demonstration of a 
link between consultation practices, alterations in the treatment setting (e.g., change in consultee behaviors or environmental manipulations), and child behavior change can help support conclusions regarding efficacy (Noell \& Witt, 1996). The identification of practical approaches to address these relations are fruitful areas of behavioral consultation and $\mathrm{CBC}$ research.

Finally, there is a need to explore the relative contribution of $C B C$ to other forms of consultation and intervention through methodologically sophisticated means. Multiple treatment designs may allow for clear statements regarding the differential efficacy of $C B C$ versus other forms of consultation (e.g., parent only or teacher only). Likewise, the direct comparison of CBC and other forms of consultation and intervention would be desirable if mechanisms could be identified to allow for the use of appropriate comparative designs (e.g., alternating or simultaneous treatment designs). Components analyses of package interventions, such as the CBC-SST package used in this study, should also be conducted to identify the differential effects of various treatment elements in producing desired behavior change.

\section{ACKNOWLEDGMENTS}

Preparation of this article was supported in part by the U.S. Department of Education, Office of Special Education and Rehabilitative Services, Grants H02950043 and H029F50053. The opinions expressed herein are those of Denise L. Colton and Susan M. Sheridan and do not necessarily reflect the views of the U.S. Department of Education.

We greatly appreciate the assistance of Drs. William R. Jenson, Karen Malm, and Anne Taverne in the development and completion of this research. We extend special thanks to Brian Martens, who provided extensive feedback regarding previous drafts of this article.

\section{REFERENCES}

Abikoff, H. (1985). Efficacy of cognitive training interventions in hyperactive children: A critical review. Clinical Psychology Review, 5, 479-512.

Achenbach, T. M., \& Edelbrock, C. S. (1991a). Manual for the Child Behavior Checklist and Revised Child Behavior Profile. Burlington, VT: University of Vermont, Department of Psychiatry.

Achenbach, T. M., \& Edelbrock, C. S. (1991b). Manual for the Teacher Report Form and Teacher Version of the Child Behavior Profile. Burlington, VT: University of Vermont, Department of Psychiatry. 
Barkley, R. A. (1990). Attention deficit hyperactivity disorder: A handbook for diagnosis and treatment. New York: Guilford.

Christenson, S. L. (1990). Differences in students' home environments: The need to work with families. School Psychology Review, 19, 505-517.

Christenson, S. L. (1995). Best practices in home-school partnerships. In A. Thomas \& J. Grimes (Eds.), Best practices in school psychology-III (pp. 253-267). Washington, DC: National Association of School Psychologists.

Comer, J. P., \& Haynes, N. M. (1991). Parent involvement in schools: An ecological approach. The Elementary School Journal, 91, 271-278.

Galloway, J., \& Sheridan, S. M. (1994). Implementing scientific practices through case studies: Examples using home-school interventions and consultation. Journal of School Psychology, $32,385-413$.

Gresham, F. M., \& Elliott, S. N. (1990). The Social Skills Rating System. Circle Pines, MN: American Guidance Service.

Kratochwill, T. R., \& Bergan, J. R. (1990). Behavioral consultation in applied settings: An individual guide. New York: Plenum.

Landau, S., \& Moore, L. A. (1991). Social skill deficits in children with attention-deficit hyperactivity disorder. School Psychology Review, 20, 235-251.

Levin, H. (1987). Accelerated school for disadvantaged students. Educational Leadership, 44(6), 19-21.

McCarney, S. B. (1991). Attention deficit disorders evaluation scale (ADDES). Columbia, MO: Hawthorne.

McGinnis, E., \& Goldstein, A. P. (1984). Skillstreaming the elementary school child: A guide for teaching prosocial skills. Champaign, IL: Research Press.

Noell, G. H., \& Witt, J. C. (1996). A critical evaluation of five fundamental assumptions underlying behavioral consultation. School Psychology Quarterly, 11, 189-203.

Pelham, W. E., \& Bender, M. E. (1982) Peer relationships in hyperactive children: Description and treatment. In K. D. Gadow \& I. Bialer (Eds.), Advances in learning and behavioral disabilities: A research annual (Vol. 1, pp. 365-436). Greenwich, CT: JAI.

Robinson, E. L., \& Fine, M. J. (1994). Developing collaborative home-school relationships. Preventing School Failure, 39, 9-15.

Scruggs, T. E., Mastropieri, M. A., \& Casto, G. (1987). The quantitative synthesis of single-subject research: Methodology and validation. Remedial and Special Education, 8(24), 24-33.

Sheridan, S. M., \& Colton, D. L. (1994). Conjoint behavioral consultation: A review and case study. Journal of Educational and Psychological Consultation, 5, 211-228.

Sheridan, S. M., \& Kratochwill, T. R. (1992). Behavioral parent-teacher consultation: Conceptual and research considerations. Journal of School Psychology, 30, 117-139.

Sheridan, S. M., Kratochwill, T. R., \& Bergan, J. R. (1996). Conjoint behavioral consultation: A procedural manual. New York: Plenum.

Sheridan, S. M., Kratochwill, T. R., \& Elliott, S. N. (1990). Behavioral consultation with parents and teachers: Applications with socially withdrawn children. School Psychology Review, 19, 33-52.

Silver, L. B. (1992). Attention-deficit hyperactivity disorder: A clinical guide to diagnosis and treatment. Washington, DC: American Psychiatric Association.

Swap, S. M. (1992). Parent involvement and success for all children: What we know now. In S. L. Christenson \& J. C. Conoley (Eds.), Home-school collaboration: Enhancing children's academic and social competence (pp. 53-80). Silver Spring, MD: National Association of School Psychologists.

Tawney, J. W., \& Gast, D. L. (1984). Single-student research in special education. Columbus, OH: Merrill. 
Von Brock, M. B., \& Elliott, S. N. (1987). Influence of treatment effectiveness information on the acceptability of classroom interventions. Journal of School Psychology, 25, 131-144.

Weiss, G., \& Hechtman, L. T. (1993). Hyperactive children grown up: ADHD in children, adolescents, and adults (2nd ed.). New York: Guilford.

Welch, M., \& Sheridan, S. M. (1995). Educational partnerships: Serving students at risk. Fort Worth, TX: Harcourt Brace.

Whalen, C. K., \& Henker, B. (1985). The social worlds of hyperactive (ADD-H) children. Clinical Psychology Review, 5, 447-478.

Witt, J. C., \& Elliott, S. N. (1985). Acceptability of classroom management strategies. In T. R. Kratochwill (Ed.), Advances in school psychology (Vol. 4, pp. 251-288). Hillsdale, NJ: Lawrence Erlbaum Associates, Inc.

Denise L. Colton, MS, is a doctoral candidate in School Psychology at the University of Utah. Her research interests include conjoint behavioral consultation, inclusion, and academic interventions for children with learning problems.

Susan M. Sheridan, PhD, is an associate professor in Educational Psychology (School Psychology) at the University of Utah. She is the coauthor of Conjoint Behavioral Consultation: A Procedural Manual and Educational Partnerships: Serving Students at Risk. Her research interests include conjoint behavioral consultation, consultation training, educational partnerships, and social skills interventions. 